\title{
E-WASTE CHALLENGES OF DEVELOPING COUNTRIES
}

\author{
Predrag Tončev ${ }^{1}$ \\ Dragan Ugrinov ${ }^{2}$ \\ Jalal Guider ${ }^{3}$
}

DOI: https://doi.org/10.31410/LIMEN.S.P.2019.129

\begin{abstract}
In recent years, increasing amount of e-waste has been a threat not only to public health but also for the environment. The problems regarding this multipart issue in developing world are raising community awareness and invest in infrastructure. The focus of this study is assessment of applied integrated approach toward electronic waste management and sustainability within organisations and to investigate if there is an environmental case for linking e-waste management with sustainable development goals regarding pollution control.

The objectives of the article include the presentation of the current situation and the pace of sustainable development in e-waste management, which is one of the major problems of modern civilization. The social aspect is dominant sustainability factor in achieving balance between health and environmental issues. The importance of social factor reflects in the level of public awareness and knowledge in this field. The obtained results clearly indicate that developing countries lack the sustainable e-waste management and social initiatives, thus releasing harmful substances into environment. Also, as a result of this research there are several targets to strive for concerning EWM in developing world: (1) to connect the community and signify the importance of saving the environment; (2) to provide environmental education workshops for adults and teenagers. (3) to give attention that trash is valuable resource (4) to practice the concept of ,"reduce, reuse, and recycle” regard decreasing health risk.
\end{abstract}

Keywords: Developing countries, E-waste, Recycling.

\section{INTRODUCTION}

A s the result of advance in technology, certain technological solutions become obsolete very fast after leaving the production facilities. This causes the production of electronic devices in the world to increase continuously. However, the increased demand for electronic goods is greatly influenced by other factors. This is primarily related to changes in the lifestyle of the population and to some extent to the growth of purchasing power. The problem of electronic waste is largely affecting developing countries. In those countries there is a growing problem of e-waste processing. This fact is influenced by insufficiently developed awareness of its harmful effects on the environment, as well as the fact that the procedures for proper storage of the e-waste and its processing are in conflict with the amount of waste generated in those countries. The aim of this paper is to highlight the specific problems facing developing countries, as well as to identify possible ways in which the problems identified can be addressed. Several targets have been proposed to improve the situation with the present e-waste management problem.

1 University „Union - Nikola Tesla“, School of Engineering Management, Bulevar vojvode Mišića 43, Belgrade, Serbia

2 University „Union - Nikola Tesla“, School of Engineering Management, Bulevar vojvode Mišića 43, Belgrade, Serbia

3 University „Union - Nikola Tesla“, School of Engineering Management, Bulevar vojvode Mišića 43, Belgrade, Serbia 


\section{LITERATURE REVIEW}

\subsection{E-waste as a health risk}

E-waste contains numerous hazardous materials: lead, mercury, and chromium, certain chemicals in plastics, and brominated flame retardants. The most worrying is the fact that some naturally occurring substances which we use in the manufacture of electronic equipment, become dangerous when they go through the production process. It should be noted that they are completely harmless in their natural appearance (Okunola Alabi \& Adekunle Bakare, 2017). On the other hand, processing of one tonne of e-waste results in a quantity of about $40 \mathrm{~kg}$ of material in the form of fine dust containing metals that are otherwise toxic in their original form (Gupta, Laul \& Syal, 2008). E-waste accounts for 0.1 to $3 \%$ of total waste on the planet, however, it should be noted that e-waste is the fastest growing waste category on the planet, which can cause many problems in the future (Martin \& Harris, 2017). The worrying fact is that product life cycle of electronic good is now reduced to three years period of time after initial purchase. People tend to change their electronical equipment more often and huge number of electronic devices will become unwanted at some point in their existence. That fact leads to the 8 percent annual growth rate in filed the e-waste industry (Martin \& Harris, 2017). According to Pinto (2008), electronic equipment is classified into three categories: white goods (mostly household appliances), brown goods (cameras, camcorders, etc.) and ultimately grey goods, which are essentially the most complex for recycling because they contain a large amount of potentially harmful substances (scanners, printers, computers, etc.).

All those hazardous materials pose a significant risk to our environment through soil and water contamination, air pollution, soil and water contamination. They present significant danger to human health and wildlife. Dioxins and furans from poly vinyl chloride cause reproductive and developmental problems and pose great threat to immune system. They can be found in plastic which is used for bodies of electronical equipment. Lead causes damage to central and peripheral nervous systems, blood systems and kidneys. Lead can be found in television or monitors screens, and in various circuit board components. Mercury poses a serious threat to the brain, respiratory system and skin. It worth to mention that Mercury can be found in various types of batteries, inside flatpanel displays, which means that there is no rule that flat panels are completely hazard free compared to cathode ray tube screens. Cadmium causes massive neural damage, while Beryllium causes chronic beryllium disease and its inhalation could result in lung cancer. Cadmium can be found in plastics, plated steel, and inside TV vacuum tubes. Beryllium is present in circuit boards and in microprocessors. Exposure to Polybrominated diphenyl ethers (PBDEs) increases the chance of getting a malignant tumour and greatly affects the normal functioning of the thyroid gland. PBDEs are used as flame retardants, but also, they can be found in products such as cell phones, TVs or personal computer and laptops (Annamalai, 2015). In addition to the harmful substances that were essentially true to electrical devices, they also contain large amounts of personal information that use unblemished tuning and can be easily misused. Nearly $70 \%$ of data that is tampered with is taken from electrical devices with memory being disposed of improperly. So, apart from the damage done to the environment, there is a problem of misuse of private data (Martin \& Harris, 2017).

\subsection{E-waste and developing countries}

Electronic waste has emerged as one of the most important issues of waste management and environmental concern, and pose a great threat to the environment due to the large volume of production of goods falling into that category of waste, as well as many other factors that charac- 
terize each country individually. The problem of electronic waste is particularly pronounced in underdeveloped and developing countries. There are many reasons for this, but in the focus will be only some of the most important. Due to lack of financial resources, developing countries are putting little effort into e-waste treatment plants. In addition, developing countries in conjunction with other factors, become a kind of landfill for this type of waste for developed countries. Namely, the worn-out and outdated technique that falls into the category of electronic waste, instead of being disposed of and properly treated, ends up on the black market where it is sold as second-hand goods. Not only developing countries are unable to cope with the electronic waste that they generate, but also, they have to cope with the waste that accumulates in the form of used electronic equipment. For example, it is worth pointing out that approximately $50-80 \%$ of the electrical waste collected in the US ends up through various channels in China, India, Pakistan, and Taiwan, as well as in countries on the African continent, more specifically in developing countries (Monika, 2010). The US, Japan and the European Union are the leading exporters of e-waste and in 2010 they exported almost 4.49 million tonnes, and it should be emphasized that India alone stores $44 \%$ of e-waste more than it generates (Sthiannopkao \& Wong, 2013). If one considers the fact that developing countries are prevented from dramatically improving their health care system, and here we are primarily thinking about the prevention and early detection of diseases that can be fatal to humans, the situation becomes quite alarming. There is a widespread trend in developing countries that very little attention is paid to develop awareness of both the harmfulness of electronic waste and the mobilization of the entire community to become more actively involved in the process of collection and treatment of electronic waste.

It seems somewhat contradictory to impose on some societies the imperative that they should actively advocate for the spread of awareness about the harmfulness of electronic waste, while keeping the broader population living below the subsistence level. Saying "The one man garbage saying, is another man treasure", can be viewed in two ways: in developed and developing countries. In developed countries, thanks to the awareness of the need for environmental protection and sustainable development, they are largely transforming their electronic waste into some kind of treasure. When it comes to developing countries, the aforementioned maxim makes sense, but takes on a rather different connotation. For example, a technologically overrun TV set that can be viewed as a good candidate by developed country residents for something that is considered as a sustainable development, is in the same time a perfectly correct electronic device for an individual in an undeveloped country that meets one's needs. It is also important to note that by the year 2030, nearly 400-700 million computers will be discarded in developing countries, which is roughly twice as much as in developed countries (Garlapati, 2016).

\section{KEY TARGETS TO DEAL WITH EWM IN DEVELOPING WORLD}

This research proposes four step model for addressing the challenges of Electronic waste in developing countries.

The first step in addressing the challenges posed by electronic waste would be to establish contacts with the community to emphasize the importance of the need to preserve the environment. If representatives of government bodies and organizations promoting the need for environmental protection succeed in reaching the broadest population, it is a very challenging task for the same community to receive the necessary attention and convince them of the importance of protecting the environment. There are different approaches through which this specific goal can be achieved. It is necessary to provide as much information as possible using the media 
or through direct contact with the community by organizing the distribution of brochures and pamphlets highlighting the need for environmental protection. It is extremely important to pay close attention to the youngest generations. Lessons learned in early childhood become an integral part of human education. Basically, only when this step is fulfilled and some kind of attention in the community is created, the conditions for more active work with adults and teenage population can be created.

The second step, a very significant phase, would involve the creation of environmental educational workshops designed for teenage population and the adults. These workshops would consist courses and lectures that might seem to be interesting to the younger population. In these workshops, teens can learn how they can do useful things like electronic robots or other gadgets from electronic waste. So-called waste recycling events can also be organized where adults and teenagers can collect items such as: cell phones, laptops, computer monitors, TVs, PC, printers, cartridges for printers, all kinds of computer cables or cords, MP3 players, DVD players, and household appliances like fans, vacuum cleaners, cooktops, dishwashers, microwaves, ovens, stoves, refrigerators, freezers, and other household hazardous waste. As for adults, it must be emphasized how important it is to properly treat e-waste and remind them that it is a debt they have towards their children and future generations. Workshops designed for adults and teens will definitely take different forms, but they will share a common commitment to protect the environment.

The third step would be the fact that it is very important to send a clear and unambiguous message that e-waste is actually a very valuable resource that is not given enough attention. Thanks to e-waste processing, we come into possession of very valuable materials such as iron, aluminium, copper, gold, silver and other precious metals (Heacock et al., 2016). It should be noted that the purity of gold obtained by processing e-waste is $80 \%$ higher than that found in natural form. Nearly 7\% of the world's gold reserves are ,trapped” in electronic waste (TCE, 2016). It is worth noting that some developing countries do not have developed facilities for the treatment of waste, but efforts can be made that to at least e-waste actively collect, as well as to properly remove it from illegal landfills, playgrounds and other sites which are not intended for storage.

The fourth step would be to act to embody the concept of ,,reduce, reuse, and recycle" with respect to reducing health risk. Reduce, reuse and recycle are the main principles of waste management (Papa, 2015).

The first principle implies that essentially the population would have to spend less to generate less e-waste. The vast majority of users are in the habit of replacing their mobile phones with a newer model after a relatively short period of time, even though the old one was in perfectly good condition. With the development of technology, devices are becoming faster, they have advanced features, but these technological leaps certainly do not happen e.g. once a year. So, obviously, this is not about the need for more modern technology to make a job easier or more efficient, but about the need to follow fashion trends and where, say, mobile phones become a status symbol. The troubling fact is that this phenomenon is particularly noticeable in the younger generation

The second principle is reuse. The essence of reusing is in finding ways to reuse electronic goods and not to dismiss them as unusable. This can be shown in the following example. Every two years, a new generation of computer processors emerges, bringing with it a new socket on 
the motherboard. If your configuration is correct and if you are a passionate video game fan, it is more than enough to replace the graphics card to give you the full experience of playing new titles. It is certainly unnecessary to change a complete computer. The average life of a computer used for business purposes is 3 to 5 years. After this time period, there may be problems with the software and hardware on computer after this time has elapsed. Also, there is a possibility that the configuration is not able to support modern programs. In such a situation, if the company is forced to retrieve computer technology, it would be beneficial to donate the used equipment to a school or non-profit organization (Sarokin, 2019). When we speak about personal computers, there is a tendency that if there is a malfunctioning part of the computer (for example, power supply), the whole computer is considered defective instead of just replacing a specific component. The reasons for this situation are reflected in the fact that users are not able to replace the component that failed on the computer themselves, as well as the fact that the repair services are extremely expensive. It is often a more tempting option for users to write off some of their computer equipment than to service it and extend its life span.

If your device, more specifically, an electronic device cannot be reused, it is very important that it is recycled properly. It is very important to highlight the fact that it is necessary to organize e-waste collection actions, especially among the younger population. Work must be done with large technical goods retail chains to install counters for disposal of used electronic equipment that cannot be used or donated as part of their sales facilities. The use of resources generated by recycling greatly reduces the need for resources available in nature. In this case, the amount of energy required for processing e-waste is far less than the energy required to obtain those same resources, for example during excavation in mining shafts (Yang et al. 2020). It should be borne in mind that recycling techniques must be constantly improved and that due care must be taken to protect the employees of those facilities. There are numerous examples where poor working conditions and outdated technology in recycling facilities have threatened the health of not only employees, but also their family members (Ceballos \& Dong, 2016).

\section{FUTURE RESEARCH DIRECTIONS}

Future research will focus on specific practices that can be used to more efficiently collect and recycle e-waste in developing countries. Particular attention will be paid to educational institutions and how young generations can be educated about the benefits of recycling e-waste to society. The essence of a successful fight for the conservation of the environment lies in raising awareness of the threat posed to the human species by the dangers of e-waste. An example of Japan should be cited. Thanks to good recycling legal solutions, nearly $74 \%$ of e-waste goes to recycling plants, while at the same time in the US this percentage is $12.5 \%$ (Sthiannopkao \& Wong, 2013).

\section{CONCLUSION}

As shown in this paper, developing countries face many challenges when it comes to dealing with e-waste management. In the face of such challenges, developing countries can follow good practices of developed countries and, in accordance with their specificities, modify the ways in which these problems can be addressed. In addition to the legal procedure, the four-step model discussed in this paper can be very effective in solving problems of electronic waste management in developing countries. It is not necessary to cultivate the illusion that the situation will change radically fast. Electronic devices will continue to be manufactured, but it is up to us to 
dispose of and recycle them properly when discontinued. This model is especially important when considering the fact that over time, developing countries generate more electronic waste, both from their own sources and through imports from developed countries. With a responsible approach, developing countries can significantly raise the level of recycling of electronic waste with the prospect of reaching the maximum possible level in the near future.

\section{REFERENCES}

Alabi, A. O., \& Bakare, A. A. (2017). Genetic damage induced by electronic waste leachates and contaminated underground water in two prokaryotic systems. Toxicology Mechanisms \& Methods, 27(9), 657-665. https://doi.org/10.1080/15376516.2017.1349228

Annamalai, J. (2015). Occupational health hazards related to informal recycling of E-waste in India: An overview. Indian Journal of Occupational \& Environmental Medicine, 19(1), 61-65. https://doi.org/10.4103/0019-5278.157013

Ceballos, D. M., \& Dong, Z. (2016). The formal electronic recycling industry: Challenges and opportunities in occupational and environmental health research. Environment International, 95, 157-166. https://doi.org/10.1016/j.envint.2016.07.010

Heacock, M., Kelly, C. B., Kwadwo Ansong Asante, Birnbaum, L. S., Bergman, Å. L., Bruné, M.-N., ... Sly, P. D. (2016). E-Waste and Harm to Vulnerable Populations: A Growing Global Problem. Environmental Health Perspectives, 124(5), 550-555. https://oi.org/10.1289/ ehp.1509699

Garlapati, V. K. (2016). E-waste in India and developed countries: Management, recycling, business and biotechnological initiatives. Renewable and Sustainable Energy Reviews, 54, 874-881. https://doi.org/10.1016/j.rser.2015.10.106

Gupta, V., Laul, P., \& Syal, S. (2008). E-waste -- A waste or a fortune? Current Science (00113891), 94(5), 554-555. Retrieved from http://search.ebscohost.com/login.aspx?direct $=$ true $\& \mathrm{db}=\mathrm{a} 9 \mathrm{~h} \& \mathrm{AN}=31688836 \&$ site $=$ ehost-live

Martin, K. B., \& Harris, C. (2017). An Analysis of E-waste: When Do Electronics Die? Journal of the Indiana Academy of the Social Sciences, 17(1), 16-24. Retrieved from http://search. ebscohost.com/login.aspx?direct $=$ true $\& \mathrm{db}=\mathrm{a} 9 \mathrm{~h} \& \mathrm{AN}=129365579 \&$ site $=$ ehost-live

Monika, J. K. (2010). E-Waste Management: As a Challenge to Public Health in India. Indian Journal of Community Medicine, 35(3), 382-385. https://doi.org/10.4103/0970-0218.6925

Papa, M. (2015). Sustainable Global Governance? Reduce, Reuse, and Recycle Institutions. Global Environmental Politics, 15(4), 1-20. https://doi.org/10.1162/GLEP_a_00324

Pinto, V. N. (2008). E-waste hazard: The impending challenge. Indian Journal of Occupational \& Environmental Medicine, 12(2), 65-70. https://doi.org/10.4103/0019-5278.43263

Sarokin, D. (2019). What Is the Life Span of the Average PC? Chron. Available at: https://smallbusiness.chron.com/life-span-average-pc-69823.html

Sthiannopkao, S., \& Wong, M. H. (2013). Handling e-waste in developed and developing countries: Initiatives, practices, and consequences. Science of the Total Environment, 463-464, 1147-1153. https://doi.org/10.1016/j.scitotenv.2012.06.088

Simple extraction of gold from e-waste. (2016). TCE: The Chemical Engineer, (904), 23.

Retrieved from http://search.ebscohost.com/login.aspx?direct=true\&d$\mathrm{b}=\mathrm{a} 9 \mathrm{~h} \& \mathrm{AN}=118805255 \&$ site $=$ ehost-live

Yang, H., Zhang, S., Ye, W., Qin, Y., Xu, M., \& Han, L. (2020). Emission reduction benefits and efficiency of e-waste recycling in China. Waste Management, 102, 541-549. https://doi.org/10.1016/j.wasman.2019.11.016 